\title{
Defendant Characteristics and Judgment Behaviors of Adolescent Mock Jurors
}

\author{
Adele M. Ackerman, ${ }^{1}$ Pamela M. McMahon, ${ }^{2}$ \\ and Lawrence A. Fehr ${ }^{3}$
}

Received July 21, 1982; accepted April 18, 1984

Fictitious court cases involving child abuse were presented to 140 male undergraduates and 140 male junior high school students to determine if the tendency to deal harshly with alleged criminals is dependent upon certain defendant characteristics. Results indicate that younger adolescent jurors give longer sentences than older adolescent jurors, and male defendants receive longer sentences than female defendants. While no significant main effects for case content were found, younger jurors gave longer sentences and attributed more responsibility to a parent who beat his/her child, while older adolescent jurors attributed more responsibility and prescribed longer sentences to a parent who burned the child. Implications for future research with adolescent jurors are discussed.

\section{INTRODUCTION}

A review of the research related to mock juror decisions indicates that specific characteristics of the defendant and/or victim, though legally irrele-

\footnotetext{
'Received Ph.D. from Lehigh University.Major interests include adolescent and adult personality and social development, developmental abnormalities, and jury behavior.

'Posidoctoral Fellow, University of Michigan. Received Ph.D. from Lehigh University. Major interests are personality and sex-role development, and psychology and the law.

'Assistant Professor, Social Science Division, Widener University. Received Ph.D. from the University of Cincinnati. Major interests are cognitive development, guilt feelings, and jury behavior.
} 
vant, have a significant effect on trial outcomes. Such characteristics include the social respectability of the victim (Jones and Aronson, 1973), the physical atractiveness of the defendant (Feild, 1979; Jacobson and Berger, 1974; Miller, 1970) and the race (Bullock, 1961), age (Fischer et al., 1982; Kalven and Zeisel, 1966), physical condition (Fischer et al., 1982) and social status (Bray, 1978) of the defendant.

The present study restricted its focus to the examination of biases resulting from characteristics of the defendant and victim in child abuse cases. Research by Fischer et al. (1982) and a review of mock juror research (Gerbasi et al., 1977) suggest that the sex of the defendant and the victim and the interaction between these two factors may have an effect upon juror behaviors.

The purpose of this research was to extend the available findings by investigating the effect of defendant and victim sex upon adolescent juror behaviors, defined as percentage of fault attributed to the defendant versus the victim and the length of the prison sentence given to the defendant.

At present, there is a dearth of research investigating the judgment behaviors of adolescent jurors. In light of the apparent success of peer jury decisions upon recidivism rates among juvenile offenders in the Denver County Juvenile System, systematic study is required to develop an understanding of adolescent decision-making processes (Steinberg, 1982).

The researchers hypothesized that, based upon the wealth of data gleaned from moral judgment research, younger adolescent jurors would be more punitive than older adolescent jurors, since younger subjects demonstrate a tendency to perceive just punishment in terms of degree of or strength of punishment. That is, the more "just" punishment should also be the most severe (Kohlberg and Kramer, 1969).

It was also hypothesized that older adolescents would attribute more of the responsibility to the adult defendant in a child abuse situation than would younger adolescents, since the older adolescents would be more proximal to assuming parental responsibilities than the junior high school males and thus more likely to hold the parent responsible for his/her behavior.

Finally, it was hypothesized that jurors would be most punitive in cases where the defendant was male. Traditional sex-role perception ascribes responsibility for control of strength to males within our culture. Lack of such restraint (i.e., engaging in aggression against his child) would warrant more serious sanction than lack of restraint by a female parent, who is not similarly constrained. 


\section{METHOD}

\section{Subjects}

The $S$ s were 140 undergraduate males drawn from an introductory psychology subject pool at Lehigh University (mean age $=19.25$ years) and 140 male junior high school students from a northeastern public school system (mean age $=14.36$ years). The subjects were all White, middle to upper middle class, and did not differ in terms of parental education status.

\section{Procedure}

Each subject participated in one test session in which he had been randomly assigned to one of four stimulus conditions ( 35 subjects per condition). All $S$ s were administered a personal information inventory and two mock child abuse cases. Case 1 involved a male defendant and a female child victim in a violent exchange (parent beats the child). Case 2 involved one of four possible defendant/victim combinations (male/male, male/female, female/male, female/female) in an equally violent but torturous exchange (parent burned child's hands on a stove). After reading each case, $S$ s indicated the percentage of criminal responsibility belonging to the defendant and to the victim and prescribed a sentence accordingly. The evidence in all cases was designed to show the defendant clearly guilty of the alleged crime. To ensure variability in the fault attribution decisions, mildly mitigating circumstances were presented for each case.

\section{RESULTS}

Data obtained from the sex-pairing manipulation (Case 2) were submitted to 2 (sex of defendant) $\times 2$ (sex of victim) $\times 2$ (age of juror) fixed

Table 1. Mean Length of Sentence in Years for Case $2^{a}$

\begin{tabular}{lccccc}
\hline & \multicolumn{2}{c}{ Female defendant } & & \multicolumn{2}{c}{ Male defendant } \\
\cline { 2 - 3 } & Female victim & Male victim & & Female victim & Male victim \\
\hline Older adolescents & 7.03 & 5.45 & & 9.57 & 10.54 \\
Younger adolescents & 6.31 & 17.11 & & 25.26 & 13.20 \\
\hline${ }^{a} n=35$. & & & &
\end{tabular}


Table II. Analysis of Variance Summary for Length of Sentence in Years Given by Older and Younger Adolescents

\begin{tabular}{lrccc}
\hline \multicolumn{1}{c}{ Source } & \multicolumn{1}{c}{$S S$} & df & $M S$ & $F$ \\
\hline A (sex of defendant) & 4576.51 & 1 & 4576.514 & $9.095^{\circ}$ \\
B (sex of defendant) & 312.91 & 1 & 312.91 & 0.623 \\
C (age of juror) & 6860.70 & 1 & 6860.70 & $13.635^{b}$ \\
AB & 437.50 & 1 & 437.50 & 0.869 \\
AC & 1373.86 & 1 & 1373.86 & 2.730 \\
BC & 356.63 & 1 & 356.63 & 0.708 \\
ABC & 1079.36 & 1 & 1079.36 & 2.145 \\
Error & 136862.43 & 272 & 503.17 & \\
\hline
\end{tabular}

$" p<0.05$.

${ }^{b} p<0.001$.

Table III. Mean Responsibility Attributed to the Defendant in Case 2 (Percent)

\begin{tabular}{lcclcc}
\hline & \multicolumn{2}{c}{ Female defendant } & & \multicolumn{2}{c}{ Male defendant } \\
\cline { 2 - 3 } \cline { 5 - 6 } & Female victim & Male victim & & Female victim & Male victim \\
\hline Older adolescents & 83.54 & 85.25 & & 86.54 & 87.17 \\
Younger adolescents & 71.74 & 65.00 & & 64.69 & 64.14 \\
\hline
\end{tabular}

${ }^{a} n=35$.

effects analyses of variance. The first analysis, based upon length of sentence (see Table I), revealed that younger adolescent jurors give longer sentences than older adolescent jurors $(F(1,272)=13.64, p<0.05)$. It was further noted that while male defendants received the longest sentences, $F(1,272)=9.99, p<0.05)$, the sex of victim by sex of defendant interaction was not significant (see Table II).

Analysis of the percentage of responsibility attributed to the defendant and victim in Case 2 (see Table III) revealed that older adolescent jurors attributed more of the responsibility for the crime to the defendant than did the younger jurors $(F(1,272)=55.42, p<0.001)$. There were no

Table IV. Analysis of Variance Summary for Percentage of Responsibility Ascribed to Defendant by Younger and Older Adolescents

\begin{tabular}{lrrrc}
\hline \multicolumn{1}{c}{ Source } & \multicolumn{1}{c}{$S S$} & df & \multicolumn{1}{c}{$M S$} & \multicolumn{1}{c}{$F$} \\
\hline A (sex of defendant) & 39.40 & 1 & 39.40 & 0.08 \\
B (sex of victim) & 106.90 & 1 & 106.90 & 0.23 \\
C (age of juror) & 55900.90 & 1 & 55900.90 & $55.42^{\alpha}$ \\
AB & 114.40 & 1 & 114.40 & 0.24 \\
AC & 720.00 & 1 & 720.00 & 1.54 \\
BC & 405.60 & 1 & 405.60 & 0.87 \\
ABC & 232.30 & 1 & 232.30 & 0.49 \\
$\quad$ Error & 127113.50 & 272 & 467.32 & \\
\hline
\end{tabular}

${ }^{a} p<0.001$ 
Table V. Mean Length of Sentences in Years in Violent and Bizarre Cases ${ }^{a}$

\begin{tabular}{lcc}
\hline & Violent case & Bizarre case \\
\hline Older adolescents & 6.06 & 9.57 \\
Younger adolescents & 26.54 & 25.26 \\
\hline
\end{tabular}

Table VI. Analysis of Variance Summary for Case Type by Juror Age for Length of Sentence

\begin{tabular}{lrrrc}
\hline Source & \multicolumn{1}{c}{$S S$} & df & \multicolumn{1}{c}{$M S$} & $F$ \\
\hline A (case type) & 15.29 & 1 & 15.29 & 0.02 \\
B (juror age) & 11631.29 & 1 & 11631.29 & $18.61^{\text {a }}$ \\
AB $\quad$ Error & 11839.41 & 1 & 11839.41 & $18.94^{\alpha}$ \\
\multicolumn{1}{c}{ Error } & 84997.94 & 136 & 624.99 & \\
\hline
\end{tabular}

${ }^{a} p<0.005$.

significant main effects for sex of defendant or sex of victim. There were no significant defendant/victim interaction effects (see Table IV).

Data obtained from the Case 1 male defendant/female victim involved in a violent exchange (parent beats child) and from the male defendant $/ \mathrm{fe}$ male victim (Case 2, parent burns child) were submitted to two additional 2 (case type) $\times 2$ (age of juror) analyses of variance to determine the effect of case content upon adolescent juror judgment behaviors.

Consistent with the results obtained from the first set of analyses, younger adolescent jurors gave longer sentences than older jurors $(F(1,136)$ $=18.61, p<0.005$ ) (see Table V). While there was no main effect for case content type (violent versus bizarre), the age of juror by case type interaction indicated that younger jurors gave longer sentences in the violent case, while older adolescent jurors gave longer sentences to the defendants in the bizarre cases $(F(1,136)=18.94, p<0.005)$ (see Table VI).

The second analysis relevant to responsibility of the defendant (see Table VII) revealed that, consistent with previous analyses, older adolescent jurors attributed more of the responsibility for the crime to the defendant than the younger adolescent jurors $(F(1,136)=19.001, p<0.005)$. The age of juror by case type interaction was significant, indicating that older

Table VII. Mean Responsibility of the Defendant in the Violent and Bizarre Cases (Percent) ${ }^{a}$

\begin{tabular}{lcc}
\hline & Violent case & Bizarre case \\
\hline Older adolescents & 82.51 & 86.54 \\
Younger adolescents & 76.77 & 64.68 \\
\hline${ }^{a} n=35$. & &
\end{tabular}


Table VIII. Analysis of Variance Summary for Case Type by Juror Age for Percent of Responsibility of Defendant

\begin{tabular}{lrcrc}
\hline \multicolumn{1}{c}{ Source } & \multicolumn{1}{c}{$S S$} & $\mathrm{df}$ & \multicolumn{1}{c}{$M S$} & \multicolumn{1}{c}{$F$} \\
\hline A (case type) & 568.03 & 1 & 568.03 & 1.619 \\
B (juror age) & 6665.40 & 1 & 6665.40 & $19.001^{a}$ \\
AB & 2272.22 & 1 & 2272.20 & $6.48^{b}$ \\
\multicolumn{1}{c}{ Error } & 47707.04 & 136 & 350.79 & \\
\hline
\end{tabular}

${ }_{b p}^{a}<0.005$
${ }_{p}<0.05$

adolescent jurors attributed more of the responsibility for the crime to the defendants involved in the bizarre case, while younger jurors attributed more of the responsibility for the crime to the defendants involved in the violent case $(F(1,136)=6.48, p<0.05)$ (see Table VIII).

\section{DISCUSSION}

The first research hypothesis stated that younger adolescent jurors would be more punitive than older adolescent jurors. The data from both the violent and the bizarre child abuse cases clearly support this notion. Among younger adolescents, the concepts of "more" and "harsh" may be equated with more effective and more just punishment for criminal wrongdoing.

It was also hypothesized that older adolescents would attribute more of the responsibility to the adult defendant in a child abuse case than would younger adolescent jurors. Again, the data from both the violent and the bizarre child abuse cases clearly support this hypothesis. Perhaps older adolescents are in the process of reviewing the parental role responsibilities for which they may be preparing and thus may be more likely to focus their attention upon the degree to which those who are parents fulfill their parental obligations and accept responsibility for their care-giver behaviors. Similarly, younger adolescent jurors may have identified more closely with the child victims and, from this point of view, attributed more responsibility for the criminal behavior to the child victim who may have evoked parental anger and thus punishment. Another possibility may be that younger jurors assign more responsibility to child victims because of a preconception of the level of morality of adults. That is, the young jurors may perceive adults as more morally correct in their behaviors than children and therefore less blameworthy.

The final hypothesis was that jurors would deal more harshly with male than female parent defendants. The data from the Case 2 sex-pairing manipulations appear to support this trend. Male defendants were given 
longer sentences than female defendants involved in the same crime. These results seem to indicate support for the notion of an active sex-role perception which admonishes males who do not or cannot restrain their physical aggressiveness toward beings perceived to be weaker than they (i.e., females, children, pets).

Finally, while case type did not af fect the general levels of punitiveness between older and younger adolescents or the attribution of responsibility by these jurors to the defendants, case content does appear to be relevant to the judgment behaviors of different-aged jurors. Older adolescents gave longer sentences and attributed more responsibility to defendants involved in the burning behavior. This can be attributed to the older adolescents' understanding that purposely burning a child is socially unacceptable. No mitigating circumstances justify this behavior.

These results direct future research to the following unanswered areas: Sex of victim and defendant manipulations must be conducted among samples of male and female adult and varied aged adolescent jurors to investigate the potential for sex-role interpretations of child abuse cases. Future research also must seek to clarify the role of particular case content upon trends in juror behaviors (e.g., What judgment behaviors would be affected in cases of juvenile delinquency?).

The potential of adolescents to serve as juvenile jurors appears an attractive alternative to traditional adjudication of juvenile trial matters. However, future research must investigate the trend among young adolescents to be very punitive before in vivo adolescent juries come into widespread use.

In conclusion, this study is consistent with the notion that juridically irrelevant characteristics of the defendant, victim, or juror have significant effects upon juror judgment behaviors. Male defendants were held more responsible for their aggressions in child abuse cases, and younger adolescent jurors were more punitive than older adolescent jurors. More sampling with multiple classes of subjects and cases must be conducted before conclusive statements may be made concerning adolescent juror behaviors.

\section{REFERENCES}

Bray, R. (1978). The effects of defendant status on the decisions of student and community juries. Soc. Psychol. 41: 256-260.

Bullock, H. (1961). Significance of the racial factor in the length of prison sentences. J. Crim. Law Criminol. Polit. Sci. 52: 411.417.

Feild, H. (1979). Rape trials and jurors' decisions: A psychological analysis of the effects of victim, defendant and case characteristics. Law Hum. Behav. 3: 261-284.

Fischer, S., Sison, G. F., Fehr, L. A., and McMahon, P. M. (1982). Defendant characteristics and juror personality effects on judgment behaviors of mock jurors. Paper presented at Eastern Psychological Association Conference, Baltimore. 
Gerbasi, K. C., Zuckerman, M., and Reis, H. T. (1977). Justice needs a new blindfold: A review of mock jury research. Psychol. Bull. 84: 323-345.

Jacobson, S., and Berger, C. (1974). Communication and justice: Defendant attributes and their effects on the severity of his sentence. Speech Monogr. 41: 282-286.

Jones, C., and Aronson, E. (1973). Attribution of fault to a rape victim as a function of respectability of the victim. J. Personal. Soc, Psychol. 26: 214-419.

Kalven, H., and Zeisel, H. (1966). The American Jury, Little, Brown, Boston.

Kohlberg, L., and Kramer, R. (1969). Continuities and discontinuities in childhood and adult moral development. Hum. Dev. 12: 93-120.

Miller, A. (1970). Social perception of internal-external control. Percept. Mot. Skills 30: 103-109.

Steinberg, Z. (1982). Director, Denver County Juvenile Diversion Program. Personal communication. 